\title{
A Comparison of Morphogenesis of Muscles of the Forearm and Hand during Ontogenesis and Regeneration in the Axolotl (Ambystoma mexicanum)
}

\author{
II. The Development of Muscular Pattern in the Embryonic \\ and Regenerating Limb \\ Miloš Grim and Bruce M. Carlson*** \\ Department of Anatomy, Faculty of Medicine, Charles University, \\ Prague, Czechoslovakia and \\ Department of Anatomy, University of Michigan, Ann Arbor, Michigan USA
}

Received August 1, 1974

\begin{abstract}
Summary. The morphogenesis of muscles of the forearm and hand was studied in embryonic limbs of the axolotl (Ambystoma mexicanum) and compared with the course of morphogenesis in the regenerating limb of adults. The first part of the paper describes the morphogenesis of muscles ontogenetic development. The course of development, from the stage of muscle blastemas through that of the independent muscle anlagen is described for each muscle. The separation of muscle anlagen and their differentiation forms a prominent proximodistal gradient. At the same time there is a clear radioulnar gradient in the formation of muscle anlagen. Phylogenetically, this radioulnar gradient is restricted to the developing limb of Urodeles. In the second part of the paper, the morphogenesis of muscles is described in the regenerating limb. The major features in regeneration recapitulate those in the embryonic limb. Proximodistal and radioulnar gradients of development are also present in the regenerating limb. This structural similarity in development supports the viewpoint that the regeneration blastema is an integrated morphogenetic unit in which muscles differentiate according to the same genetic plan as they do in the embryo. There are some differences, however, between the regenerating and embryonic limb. The regenerating $\operatorname{limb}$ is larger, its muscle blastemas are also larger from the beginning, and the regenerating limb has a relatively greater amount of mesenchymal cells, which are not closely integrated into the muscle or skeletal anlagen.
\end{abstract}

Key words: Axolotl-Muscle development-Forelimb-Ontogenesis-Regeneration.

\section{Introduction}

A developing limb is an extremely complex morphogenetic system. Arising from a homogeneous mass of mesenchymal cells covered by ectoderm, the limb bud grows in both length and mass as the result of a continuing series of interactions between the ectoderm and the underlying cells (Saunders, 1948; Zwilling, 1961). As growth proceeds, the conical limb bud becomes molded into a form increasingly resembling that of the definitive limb. Internally, as well as externally, morphogenetic processes mold an anatomically simple and relatively homogeneous system into an intricate structural mosaic consisting of numerous skeletal and muscular elements embedded in a meshwork of connective tissue and interconnected by vascular and nervous networks.

\footnotetext{
* Supported in part by a grant from the Muscular Dystrophy Associations of America ** Some of this work was carried out during the course of scientific exchange visits from 1971-1974 sponsored by the United States and Czechoslovak Academies of Sciences.
} 
Some aspects of limb development have been exhaustively studied whereas others have been virtually neglected. The development of muscular pattern in Urodeles is one which has received very little attention. As a result, experimental studies on mechanisms of muscle morphogenesis in the regenerating amphibian limb (Carlson, 1971, 1972 a) have been hindered by the current paucity of information on the normal course of muscle development in the embryo.

Chen (1935) described the development of the forelimb of Necturus maculosus. In the part of the work devoted to the morphogenesis of muscles, he presented only basic data. His coverage did not include all of the muscles, particularly in the autopodium. The formation of the muscles in the shoulder region in Siredon pisciformis (the axolotl) was studied by Rylkoff (1924). Development of the muscles of the forearm and hand of the axolotl has not been studied.

The morphogenesis of limb muscles has been followed systematically in mammals and birds. Cihák (1972) has distinguished four temporal phases during the course of muscle morphogenesis: 1 . the origin of the blastemal layers, 2 . the formation of muscle anlagen within the blastemal layers, 3 . the reorganization of the already formed anlagen and 4 . the joining of the anlagen to the skeleton and molding of the external form of the muscles. The second and particularly the third phases are important, for the major changes constituting the process of developmental recapitulation occur during them. This knowledge has been extensively used for the study of muscle development in humans and in some experiments involving vertebrates (Čihák, 1957, 1963, 1972; Dylevský, 1967, 1968; Trnková and Dylevský, 1969; Grim, 1971).

The present investigation was initially designed to answer the following question: Does the pattern of development of the musculature in the regenerating forearm and hand of the axolotl follow a morphological course similar to that which occurs in the embryonic limb? This part of the study is divided into two sections -1 . musele development in the embryonic limb and 2. muscle development in the regenerating limb. The comparison between the ontogenetic and regenerative development of forelimb muscles shows a remarkable similarity between the two processes. These observations are made against the background of the normal anatomy in muscles of the forelimb of the adult axolotl, particularly the arrangement of the muscles in layers (Grim and Carlson, 1974). They are interpreted from the viewpoint of both the comparative embryologist and the experimental morphologist.

\section{Materials and Methods}

This investigation was carried out on early larvae and mature specimens of the axolotl (Ambystoma mexicanum), obtained primarily from the colony at the University of Michigan. All embryos and adults were maintained at a temperature of $21^{\circ} \mathrm{C}$.

In the study of embryonic development, both limbs of 25 early larvae were used. In the absence of a published series of stages for embryonic development in the axolotl, the larvae were compared with Harrison's (1969) staging of normal development in Ambystoma punctatum. Early development of the axolotl corresponds quite closely with that of $A$. punctatum, but in the later Harrison stages there are some variations between the gross development of limbs in relation to that of other bodily structures. In these cases, gross morphology of the axolotl limb was used as the key for the assigning of developmental stages.

Larvae at a more advanced state of differentiation than that corresponding to stage 46 , the last of the Harrison stages, were distinguished partly according to their size and partly 
according to external manifestations of differentiation of the limbs. At stage 46, our larvae ranged from $21-22 \mathrm{~mm}$ in total length, and on the forelimb only three digits were externally visible. In larvae $23-24 \mathrm{~mm}$ in length, the primordium of the fourth digit had also taken shape. The primordium of the hind limb has formed a small bud which elongates in larvae longer than $24 \mathrm{~mm}$. This study included larvae from stage 38 to specimens $27 \mathrm{~mm}$ in length.

All specimens from Michigan were fixed in Bouin's and embedded in Paraplast before serial sectioning. The limbs were cross sectioned at $10 \mu$ and were stained with Weigert's hematoxylin and eosin. In addition thick Epon sections of embryonic limbs from 14 additional animals, obtained from Mr. Wondreys in Prague, were used in the study.

For the study of muscle development during limb regeneration, 58 limbs were examined. Forty were taken from older animals ranging from 195 to $240 \mathrm{~mm}$ in total length. The remaining 18 limbs came from 7 month-old axolotls ranging in length from 75 to $90 \mathrm{~mm}$. In these series, the forelimbs were amputated through the middle of the upper arm and then allowed to regenerate for periods from 20-46 days in the case of the larger animals and from 13-20 days for the series of smaller animals. Because of the considerable variation in the rates of limb regeneration, it was necessary to evaluate the maturity of individual regenerates by arranging them in graded series. Gross features of critical stages in regeneration will be indicated in the description of the results. All regenerates were fixed in Bouin's, serially sectioned at $7 \mu$ and stained with Ehrlich's hematoxylin and eosin or with Heidenhain's aniline blue stain.

\section{Results}

\section{Morphogenesis of the Muscles of the Forearm and Hand during Ontogenesis}

Evidence of muscle blastema formation in the zeugopodium of the forelimb of the axolotl is not found before stage 40 , and then only in the proximal part, where the flexor and extensor muscle blastemas begin to form. At this stage, the blastemal cells have very rounded nuclei and only very little cytoplasm. The frequent occurrence of mitoses attests to the prominence of proliferative activity. The distal part of the zeugopodium and the entire autopodium are still composed of uniformly distributed mesenchymal cells. In contrast to this, muscle blastemas are already distinct at the base of the limb and in the stylopodium in stages 38-39.

Stage 42. The prochondral primordia of the proximal parts of the radius and ulna have already taken shape. The muscle blastemas are bulky and have distinet boundaries. The blastemal cells are elongated and are oriented along the proximodistal axis. The flexor blastema bulges above the course of the neurovascular bundle, and in the proximal part the blastemal cells run obliquely in a radioulnar direction. In the distal part of the zeugopodium and in the autopodium differences in the density of the cells are already becoming apparent, but muscle blastemas are not yet clearly defined. The primordium of the ray of the first digit is filled with mesenchyme. The second digit is suggested only by a protuberance of ectoderm. In the primordium of the right limb the level of morphogenesis is more advanced than it is in the primordium of the left limb.

Stage 43 (Figs. 1-3). The muscle blastemas separate further. Differences in the density and orientation of the blastemal cells allow one to distinguish certain muscle anlagen at this stage, although these are not independent and their distal parts are not yet fully formed. In the flexor blastema it is possible, because of the disposition of the nuclei, to discern the beginnings of myotube formation, although in the light microscope myofibrils are not yet clearly visible. Some cells of the muscle blastemas show a prominent basophilia and are consequently in the stage of differentiation that precedes the formation of myofibrils. 

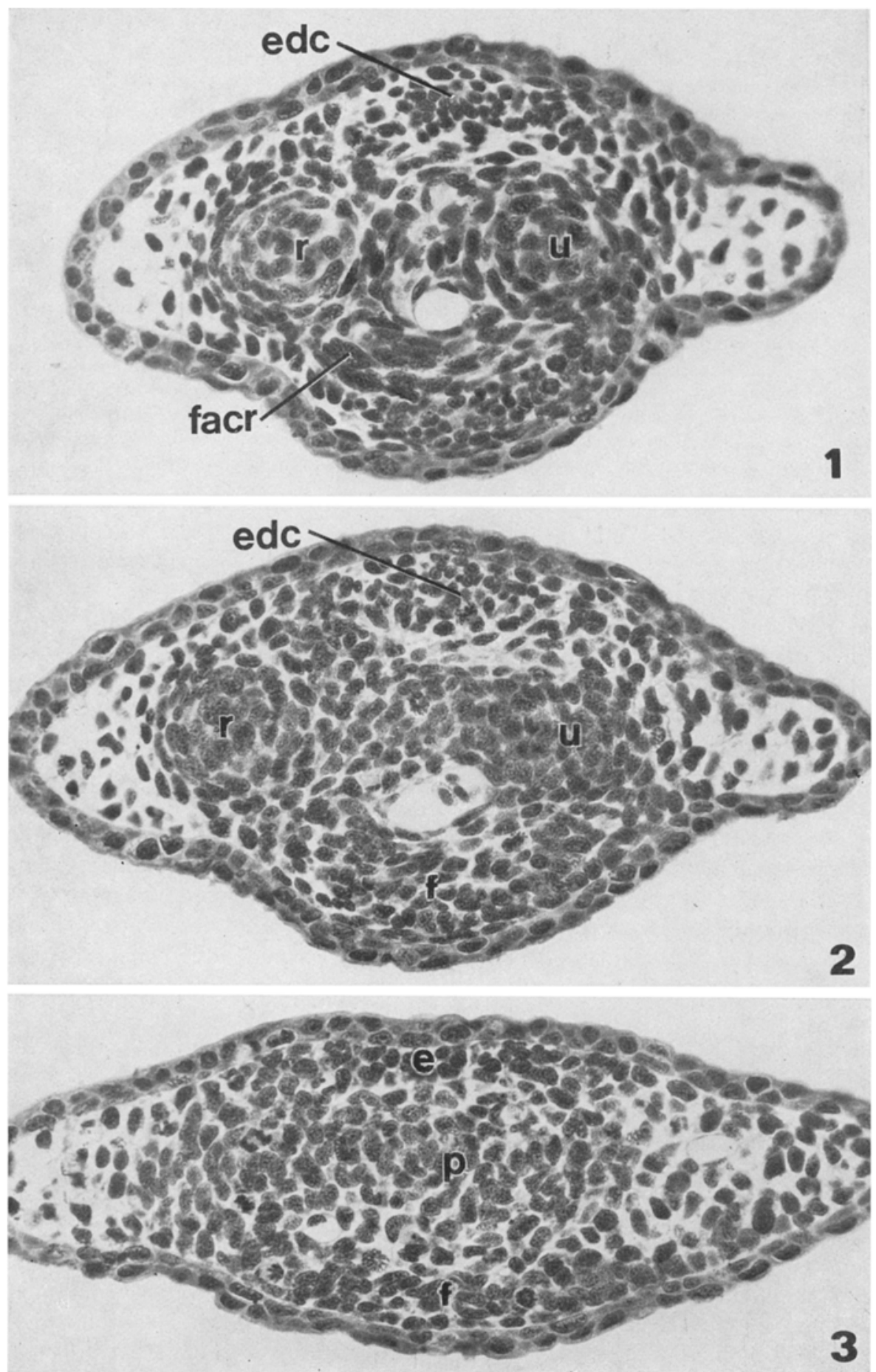

Figs. 1-3 
In the proximal third of the forearm a small layer of cells, lying superficially and in the middle, begins to detach from the extensor muscle blastema. It is clearly separated from the more deeply lying cells of the blastema whereas radially and particularly ulnarly it merges into a less well defined aggregation of cells. That partial separation of a group of cells forms the anlage of the m. extensor digitorum communis, which lies most superficially along the entire length of the forearm (Fig. 1).

The flexor blastema at stage 43 (Fig. 1) begins to separate into two parts, which differ in the orientation of their cells, but they are not yet completely detached from one another. In the radial part of the blastema the oval nuclei of the blastemal cells are oriented obliquely; in the ulnar part of the blastema the nuclei lie vertically to the plane of section. At the same time the ulnar part of the blastema partially covers the obliquely oriented cells of the radial part.

In the distal third of the forearm the degree of morphogenesis of the muscle anlagen is less advanced. In the flexor blastema the anlagen of the muscles are still not distinct. At this level in the extensor muscle blastema, however, the previously mentioned anlage of the $\mathrm{m}$. extensor digitorum communis is perceptible (Fig. 2). Its anlage is the first muscle anlage of the forelimb which can be distinguished to such an extent. In the prochondral primordia of the skeleton at this level the primordium of the radius is distinetly more mature than that of the ulna.

In the autopodium (Fig. 3) the limb bud flattens and broadens, and distally it passes into the primordia of the first two digits. In the carpal region the prochondral blastema and both muscle blastemas are just forming. Cells of the muscle blastemas are quite densely packed, particularly beneath the epidermis, and their nuclei are more basophilic than the nuclei of the cells in the prochondral blastema. The primordia of the first two digits are filled with loose mesenchyme.

Stages 44 and 45 . The anlagen of the remainder of the forearm muscles form, and in a proximodistal direction they progressively become independent entities (Fig. 4). The anlage of the $\mathrm{m}$. extensor digitorum communis was already formed in the preceding stage. Now it is separate throughout most of its length, but its origin, later a broad fibrous tendon, consists only of a very small number of mesenchymal cells. The anlagen of the remaining three extensors arise by the lengthwise splitting of the dorsal blastema. In the middle, beneath the anlage of

Fig. 1. Cross section through the proximal third of the embryonic forearm in the axolotl at stage 43. The anlage of the m. extensor digitorum communis (e.d.c.) has formed within the extensor muscle blastema. In the flexor blastema the orientation of the cells of the anlage of the $\mathrm{m}$. flexor antebrachii et carpi radialis (f.a.c.r.) differs from that of the remaining as yet undifferentiated anlagen. $r$ primordium of radius, $u$ primordium of ulna. $\mathrm{H} \& \mathrm{E} \times 205$

Fig. 2. Cross section through the distal third of the same limb shown in Fig. 1. The anlage of the m. extensor digitorum communis (e.d.c.) can be seen in the extensor muscle blastema whereas the flexor blastema $(f)$ remains undivided. The primordium of the radius $(r)$ is more highly differentiated than that of the ulna $(u)$. H\& $\mathrm{E} \times 205$

Fig. 3. Cross section through the autopodium of the same limb shown in Figs. 1 and 2. The beginnings of the flexor $(f)$ and extensor $(e)$ muscle blastemas are forming between the ectoderm and the prochondral blastema $(p) . \mathrm{H} \& \mathrm{E} \times 205$ 

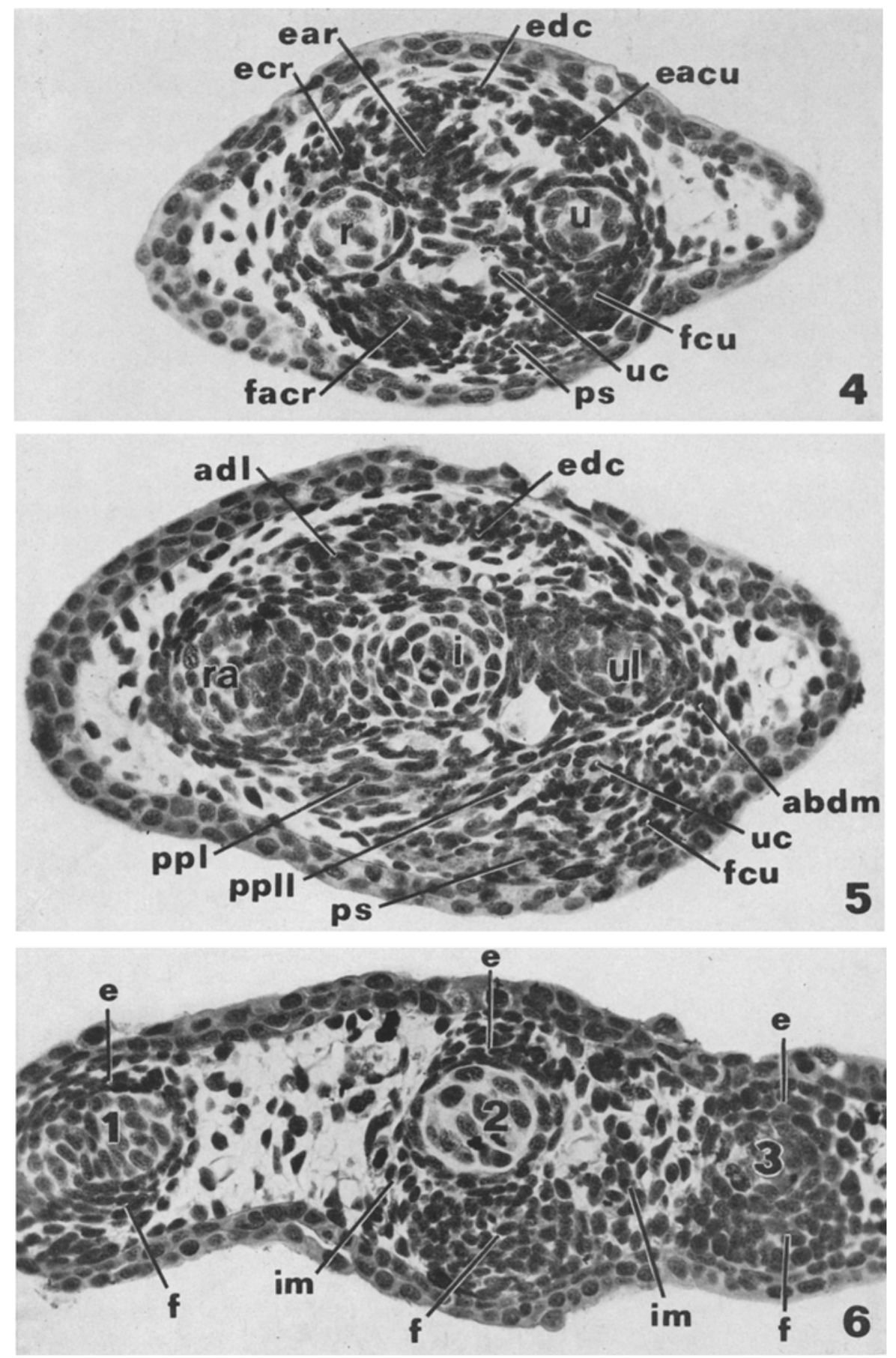

Figs. 4-6 
the long digital extensors, the anlage of the $\mathrm{m}$. extensor anterachii radialis forms. It is a massive anlage, whose myotubes run obliquely toward the radius. Radially from it the anlage of the $m$. extensor carpi radialis arises. This anlage consists of closely packed but well differentiated myotubes, which are distinguishable by their vertical orientation to the plane of section. On the ulnar side lies the quite well separated, but cytologically less differentiated anlage of the in. extensor antebrachii et carpi ulnaris. The anlage of the $\mathrm{m}$. flexor antebrachii et carpi radialis is derived from the radial part of the flexor blastema. At stage 45 it is already markedly separated and relatively well differentiated. The ulnar part of the flexor blastema divides into the anlagen of the $\mathrm{m}$. palmaris superficialis and the $m$. flexor carpi ulnaris.

The anlagen which originate on the palmar surface of the skeleton of the zeugopodium form in that part of the flexor blastema that lies between the ulna and radius. The most proximal of these muscles is the $\mathrm{m}$. ulnocarpalis. Its anlage forms during stages 44 and 45 . It is situated on the radial margin of the ulna under the anlage of the $\mathrm{m}$. flexor carpi ulnaris, and it is independent from the beginning. The anlage of the $\mathrm{m}$. pronator quadratus appears between the ulna and the radius on the lower surface of the anlage of the $\mathrm{m}$. ulnocarpalis. At stage 45 it is still poorly defined.

Distally, the deep flexor layer continues to form the anlagen of the $\mathrm{mm}$. palmares profundi I-III. These muscles run radially from the ulna and at the same time toward the surface, and are in contact with one another in a proximodistal direction. This causes difficulties in delineating their anlagen, which in cross sections cannot be readily distinguished before stage 46 . The greater part of these muscles already lies in the autopodium (Fig. 5).

The muscle blastemas of the short flexors and extensors of the digits are still poorly differentiated at stages 44 and 45 . The anlagen of the individual muscles still cannot be distinguished. Only in the palm are the future deepest layers of the

Fig. 4. Muscle anlagen in cross section in the middle of the embryonic forearm at stage 45. e.c.r. $\mathrm{m}$. extensor carpi radialis, e.a.r. m. extensor antebrachii radialis, e.d.c. m. extensor digitorum communis, e.a.c.u. m. extensor antebrachii et carpi ulnaris, f.a.c.r.m. flexor antebrachii et carpi radialis, p.s. m. palmaris superficialis, u.c. m. ulnocarpalis, f.c.u. m. flexor carpi ulnaris. $r$ cartilaginous primordium of the radius, $u$ cartilaginous primordium of the ulna. $\mathrm{H} \& \mathrm{E} \times 80$

Fig. 5. Cross section through the embryonic autopodium at the level of the proximal carpals. Stage 46 . The muscle anlagen are only incompletely separated. a.d.I $\mathrm{m}$. abductor digiti $\mathrm{I}$ et extensor brevis digiti $\mathrm{I}$, e.d.c. $\mathrm{m}$. extensor digitorum communis, p.p. $I \mathrm{~m}$. palmaris profundus primus, p.p. $I I \mathrm{~m}$. palmaris profundus secundus, p.s. m. palmaris superficialis, $f . c . u$. m. flexor carpi ulnaris, u.c. m. ulnocarpalis, $a b . d . m . \mathrm{m}$. abductor digiti minimi, ra. primordium of the os radjale, $i$. primordium of the os intermedium, $u l$. primordium of the os ulnare. $\mathrm{H} \& \mathrm{E} \times 80$

Fig. 6. Cross section through the autopodium at the level of the metacarpals in the same limb as that in Fig. 5. 1,2,3 primordia of the metacarpals in radioulnar order. In the extensor muscle blastema (e) it is for a while not yet posssible to distinguish the tendon of the long digital extensor from the anlage of the short digital extensors. The flexor muscle blastema $(f)$ is not until this time separated into anlagen of the short digital flexors. The deep part of its border, which extends between the metacarpals, is the first trace in the formation of the mm. intermetacarpales (im.). $\mathrm{H} \& \mathrm{E} \times 80$ 
flexor blastema incompletely separated from the superficial part of the blastema by the course of the arch of the $n$. ulnaris (r. prof. $n$. brachialis longi inf.). The first anlagen of the intrinsic muscles of the autopodium are not separated before stage 46 .

Stage 46. The most distinct anlage in the autopodium at stage 46 is that of the $m$. abductor et extensor brevis digiti I. It forms under the radial margin of the long extensor of the digits in an independent blastemal layer on the dorsal side of the carpus (Fig. 5). In the ulnar part of this layer appears the anlage of the short extensor of the second digit, and in later stages, also, the anlagen of the short extensors of the third and fourth digits. At the level of the metacarpals (Fig. 6) it is impossible at this time to distinguish the anlagen of the short extensors from the tendons of the long extensor. The primordium of the third digit is shorter than those of the first two radial digits, and its distal part is filled only with mesenchyme. The anlage of the m. abductor digiti minimi (Fig. 5), which until this time was poorly defined, is formed in the flexor blastema at the ulnar edge of the autopodium. The blastema of the short flexor muscles of the digits is well defined at the bases of the metacarpals (Fig. 6). The blastema itself is not until this time, however, divided into the layers of the future anlagen of the short flexors, and in addition until this time the anlagen of the short flexors have not separated from the anlagen of the $\mathrm{m}$. palmaris profundi and $\mathrm{m}$. palmaris superficialis at their areas of insertion in the palm. The deep part of its radial border protrudes into the space between the metacarpals. This protrusion is the first sign of the formation of the anlage of the mm. intermetacarpales (Fig. 6).

$24 \mathrm{~mm}$ larvae. The anlagen of all the muscles of the forearm are completely formed and separated from one another (Fig. 7). The anlagen of their tendons and aponeuroses have formed accumulations of connective tissue cells without the prominent participation of connective tissue fibers.

The anlagen of the short flexors of the digits in the autopodium can first be distinguished in larvae $24 \mathrm{~mm}$ in length. They form by the division of the flexor blastema on the palmar surface of the metacarpals into three independent layers (Fig. 8). The superficial layer corresponds to the anlagen of the $\mathrm{mm}$. flexores digitorum breves superficiales. Later in this same layer the tendons of the $\mathrm{m}$. palmaris superficialis differentiate on the side facing the epidermis. In the middle layer the anlagen of the mm. flexores digitorum breves form, and in the deep layer the anlagen of the $\mathrm{mm}$. flexores digitorum breves profundi also appear. Even before the division of the flexor blastema into three layers, the formation of the anlagen of the $\mathrm{mm}$. intermetacarpales was indicated as a protrusion of the deep part of the ulnar margin of the flexor blastema toward the intermetacarpal space (Fig. 6). In $24 \mathrm{~mm}$ long larvae the anlagen of the $\mathrm{mm}$. intermetacarpales are already well formed, and they remain in contact with the deep layer of the blastema, which corresponds to the anlagen of the $\mathrm{mm}$. flexores digitorum breves profundi. The anlagen of the $\mathrm{mm}$. flexores digitorum minimi form a distal continuation of this deep layer. The anlage of the $\mathrm{m}$. interphalangeus until this time has consisted only of a poorly defined accumulation of cells on the palmar surface of the proximal phalanx of the third digit.

26-27 mm larvae. The anlage of the superficial short flexor of the digit begins to divide into the lateral and middle parts of the definitive muscle. In the fourth 

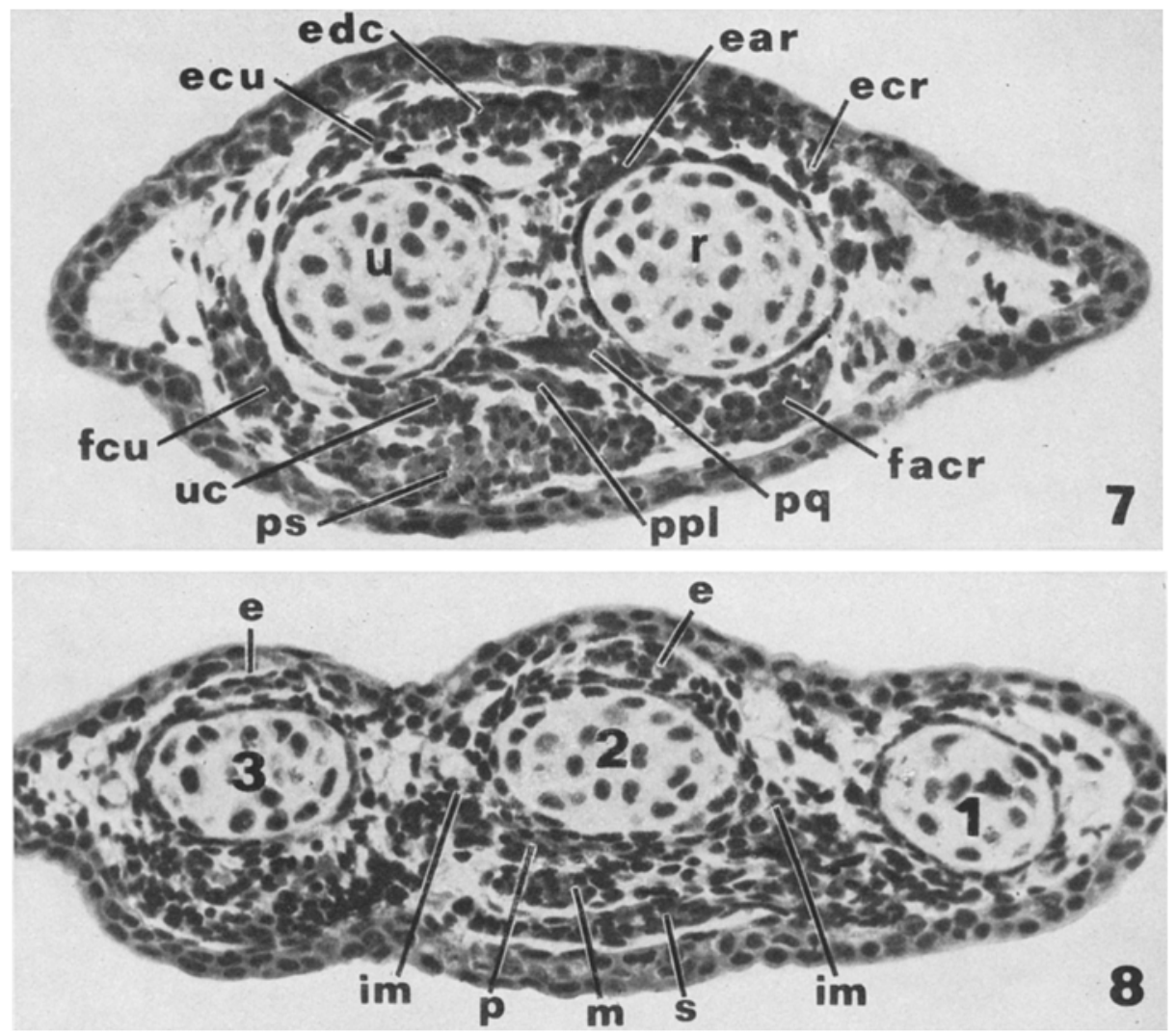

Fig. 7. Cross section through the distal third of the forearm in a larvae $24 \mathrm{~mm}$ long. The anlagen of the forearm muscles are already close to their definitive form. Muscle fibers are dominant features within them. p.q. m. pronator quadratus. The other abbreviations are the same as those in the preceding figures. $\mathrm{H} \& \mathrm{E} \times \mathbf{1 6 0}$

Fig. 8. Cross section through the autopodium at the level of the base of the metacarpals in the same limb as that in Fig. 7. The palmar muscle blastema is already divided into three independent layers - the common anlagen of the short digital flexors. The metacarpals are labelled 1.2 .3 in a radioulnar direction. $e$. anlage of the $m$. extensor digitorum brevis, $s$. anlage of the m. flexor digitorum brevis superficialis together with the tendon of insertion of the $m$. palmaris superficialis, $m$. $m$. flexor digitorum brevis medius, $p$. primordium of the $m$. flexor digitorum brevis profundus, $i m . m$. intermetacarpalis. $\mathrm{H} \& \mathrm{E} \times 160$

digit this is not yet distinctly separated, for the distal part of the digit is until this time still not completely differentiated. In these larvae the form of the muscle anlagen of the forearm is close to the definitive final form of the muscles, and one can now properly speak about individual muscles. The spaces between museles and between the muscles and the dermis is filled only with loose mesenchyme.

\section{Muscle Development in the Regenerating Limb}

It has been established in a previous study (Carlson, 1972 a) that the musculature in a fully regenerated limb of the axolotl is histologically and grossly identical 

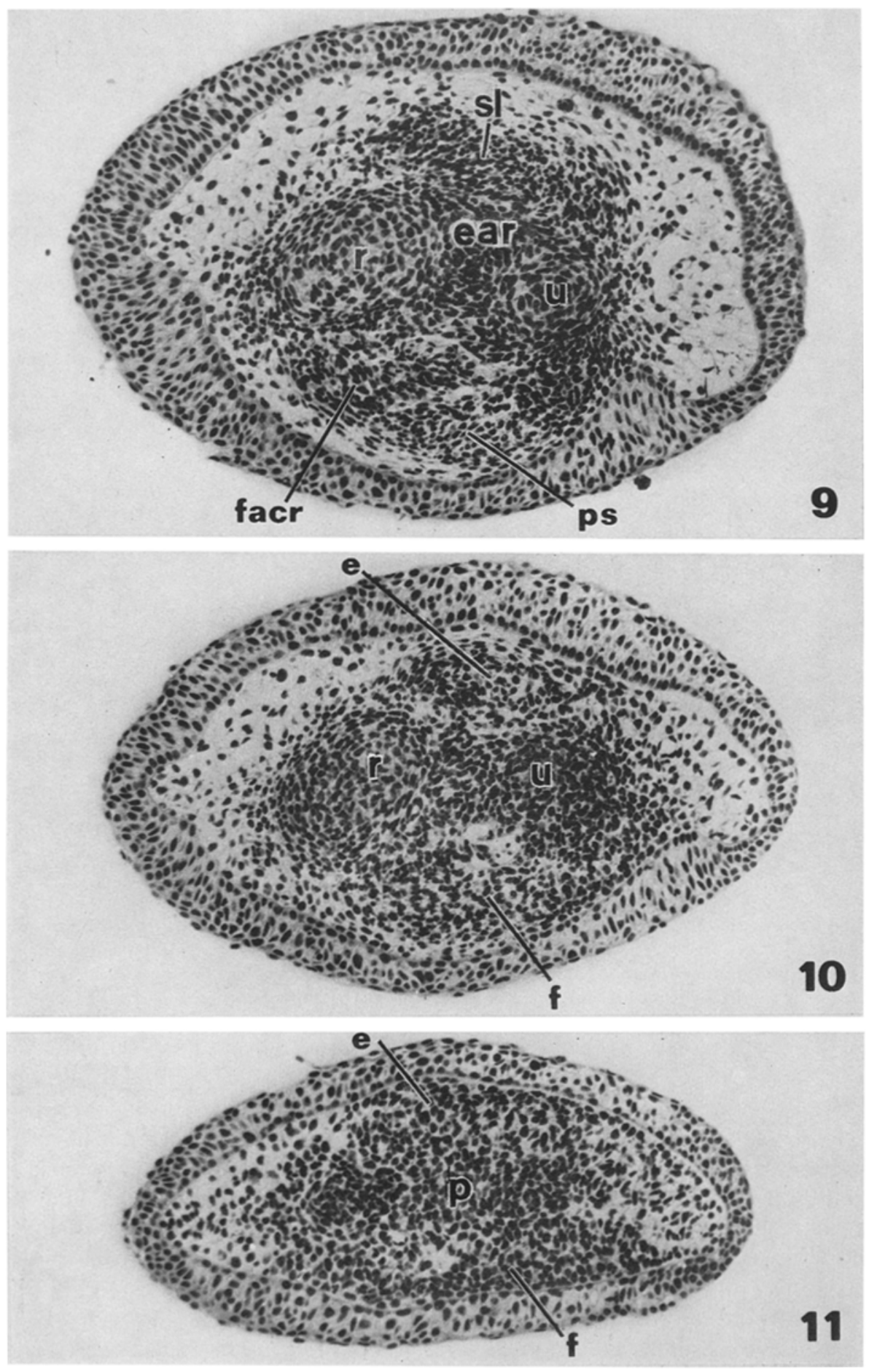

Figs. 9-11 
to that of its normal counterpart. This section will provide evidence that the pathway traversed by the regenerating muscles is, at least in the later stages, essentially a recapitulation of the ontogenetic development of these same muscles.

The first few weeks following limb amputation are devoted almost entirely to the establishment of the limb regeneration blastema, which is composed of morphologically dedifferentiated cells derived from the limb stump. The processes leading to blastema formation have been reviewed several times (Goss, 1961; Rose, 1964; Thornton, 1968; Carlson, 1974) and will not be repeated here. During the period leading up to and including that of the undifferentiated regeneration blastema it has not been possible to identify future myogenic cells by either morphological or other criteria. Thus in regeneration, as well as in embryonic $\operatorname{limb}$ development, description of muscle morphogenesis must begin with the period when the formation of the prochondral and muscle blastemas starts.

In the regenerating limb there is a strong proximodistal gradient of differentiation. Thus in a limb amputated proximal to the elbow, differentiation of the distal humerus and muscles of the upper arm has begun while the forearm and hand are still represented by a largely undifferentiated, but elongating regeneration blastema. Although the musculature of the distal upper arm is reconstituted into units corresponding to the normal muscles, the muscle fibers which have regenerated just distally to the ends of the stump musculature may not be arranged into an anatomically normal pattern. Although extensive treatment of the establishment of the upper arm musculature is beyond the scope of this paper, the pattern of the regenerated muscles is interpreted as follows: The distal well formed muscles are formed by the epimorphic mode of regeneration, involving the regeneration blastema, whereas the proximal, less organized pattern appears to represent a tissue regenerative process. Because of postamputational retraction. of the stump muscles and their subsequent differentiation as a tissue, the most proximal myoblasts were probably both spatially and temporally removed from the sphere of morphogenetic influence of the regeneration blastema as they began to differentiate (Carlson, 1970, 1972 b).

Until the first prochondral primordia of the radius and ulna are recognizable, cross sections of the forearm regeneration blastema cannot be readily analyzed.

Fig. 9. Cross section through the proximal part of the regenerating forearm in a 7 month old axolotl 17 days after amputation. The early phase of morphogenesis of the muscle anlagen in the extensor and flexor muscle blastemas. s.l. superficial layer of extensor blastema, e.a.r. anlage of the $\mathrm{m}$. extensor antebrachii radialis, f.a.c.r. anlage of the $\mathrm{m}$. flexor antebrachii et carpi radialis, $p . s$. anlage of the $m$. palmaris superficialis, $r$. primordium of the radius, $u$. primordium of the ulna. $\mathrm{H} \& \mathrm{E} \times 80$

Fig. 10. Cross section through the distal forearm of the same regenerate shown in figure 9. Muscle anlagen are not distinguishable in the distal part of the forearm. The flexor blastema $(f)$ and the extensor blastema $(e)$ are both compact. The primordium of the radius $(r)$ is more distinctly formed and its cells are more highly differentiated than are those of the primordium of the ulna $(u) . \mathrm{H} \& \mathrm{E} \times 80$

Fig. 11. Cross section through the autopodium of the same regenerate shown in Figs. 9 and 10. This level shows the stage at which the prochondral $(p)$ blastema and both muscle blastemas extensor $(e)$ and flexor $(f)$ - are formed. $\mathrm{H} \& \mathrm{E} \times 80$ 
At any level of the zeugopodium the primordium of the radius becomes established earlier than that of the ulna (Figs. 9, 10). In the smaller animals, this occurred early in the third week after amputation whereas in the larger animals the same stage wasn't attained until early in the fourth post-amputational week. During the period following the earliest formation of the skeletal primordia, muscle blastemas, representing the flexor and extensor muscle masses, can be distinguished in the proximal regions of the forearm.

Figure 9 shows a stage in which separations within the extensor and flexor muscle blastemas proceed further. It is taken from a regenerate $\mathbf{1 7}$ days after amputation in a 7 month animal. On the surfaces of both muscle blastemas bulges can be found. In the muscle blastemas themselves local variations in the density of cells are beginning to appear. In the extensor muscle blastema most of the superficial layer of the blastema separates from the part that lies along the ulnar margin of the radius. This deep but yet incompletely separate part of the extensor blastema forms the anlage of the $\mathbf{m}$. extensor antebrachii radialis. The superficial layer constitutes the still incompletely separated anlagen of three muscles: the $\mathrm{m}$. extensor carpi radialis, the $\mathrm{m}$. extensor digitorum communis and the $\mathrm{m}$. extensor antebrachii et carpi ulnaris. The flexor blastema is distinctly divided in its radial part. In it the distinct anlage of the $\mathrm{m}$. flexor antebrachii et carpi radialis and the anlage of the $\mathrm{m}$. palmaris superficialis differentiate. In the ulnar part of the blastema, only insignificantly separated from the radial side, the anlage of the $\mathrm{m}$. flexor carpi ulnaris appears.

The extensor muscle blastema is considerably smaller than the flexor blastema. Conversely there is a substantially greater mass of loose mesenchyme on the extensor side than on the flexor side of the limb. The cells within the muscle blastemas are in an early state of differentiation. Although some early myotubes are present, many of the myoblasts are in the stage just preceding fusion, in which the intensely basophilic myoblasts are aligned almost end to end (with some cytoplasmic overlap) in long rows. In the radial part of the flexor blastema the blastemal cells are more highly differentiated and have a greater amount of cytoplasm than cells in the ulnar part of the blastema.

Throughout much of the forearm, two gradients of differentiation become evident in the regenerate. The major one is a proximodistal gradient of decreasing maturity of all types of tissues. There is also evident a transverse gradient of greater maturity on the radial side and lesser maturity on the ulnar side of the limb. This is particularly striking with respect to the skeleton, but it also holds true for the soft tissues of the limb.

The region of the regenerate illustrated in figure 10 represents a transitional area. This is a section from the distal part of the forearm 17 days after amputation in a 7 month old axolotl. The primordium of the radius is more highly differentiated than that of the ulna. The muscle blastemas are distinct and clearly outlined. The flexor blastema remains compact and does not show signs of breaking up into muscle anlagen. In the extensor muscle blastema one can see a separation into superficial and deep layers, but this is still indistinet. Proximal to the transitional area the skeletal primordia are well differentiated with respect to both gross morphogenesis and eytodifferentiation (cartilaginous phase), and the muscle blastemas are beginning to separate into discrete anlagen. 
Distal to the transitional area, in the autopodium, the regeneration blastema is composed of similar appearing cells (Fig. 11). Their disposition is not uniform and suggests the beginnings of the formation of a centrally lying prochondral blastema (its radial border is more distinct) as well as extensor and flexor muscle blastemas (Fig. 11). In these blastemas there is a noticeably greater density of cells than in the radial and ulnar margins of the regenerate, but their borders are not clearly defined.

In succeeding days, maturation of the regenerate progresses rapidly distad, and the first digits become grossly visible by 19 days in smaller animals and 28 days in the larger ones. By this stage the cartilaginous skeleton of the forearm is fully established and the anlagen of the individual muscles of the zeugopodium are apparent (Fig. 12). Within the anlagen the muscle fibers are past the myotube stage, and the nuclei have begun to move toward the periphery of the individual fibers. Early cross-striations are visible.

A significant quantity of connective tissue cells is present within the anlagen, among the various anlagen and also between the muscle anlagen and the epidermis. Because of their presence within the anlagen, fasiculation of the muscles is quite pronounced. Connective tissue cells among the anlagen of the muscles obscure the boundries of the individual anlagen. This is an important difference in contrast to the ontogenetic development of the anlagen, where only a minimal number of mesenchymal cells is present.

At the level of the carpus, the $\mathrm{m}$. abductor digiti $\mathrm{I}$ is well defined on the extensor surface. The palmares profundi muscles occupy a significant portion of the flexor muscle mass, but the bounderies of the individual muscles cannot be readily defined.

In the metacarpal and phalangeal region the lateral gradient of differentiation again becomes evident. Although the skeletal elements of the first through the third digits are well differentiated, the fourth digit is represented by a mass of undifferentiated cells whose morphology resembles very closely the cells in the early regeneration blastema of the entire limb.

At the level of the metacarpals (Fig. 13) the anlagen of the short muscles of the autopodium are well formed. On the extensor surface of the second metacarpal the anlage of the short extensor is distinct. Merged with its surface is the anlage of the tendon of the long extensor. In the space between the metacarpals, the anlagen of the $\mathrm{mm}$. intermetacarpales are very distinct. The insertion of the $\mathrm{m}$. flexor digitorum brevis profundus is fastened on the palmar side of the second metacarpal at the same level. The bellies of the $\mathrm{m}$. flexor digitorum brevis medius are prominent. The division into two parts, which the muscle has in its definitive final state, is not yet clear. On its surface lie the indistinctly separated strips of the anlage of the $m$. flexor digitorum breves superficialis together with the tendon of insertion of the $\mathrm{m}$. palmaris superficialis. In the terminal portions of the first through the third digits the last vestiges of the proximodistal gradient of differentiation are represented by the presence of larger and more basophilic cells than those in the proximal region.

Normally by 1 to 2 months after amputation, depending upon the size of the animal, differentiation of both skeletal and muscular elements in the regenerating 

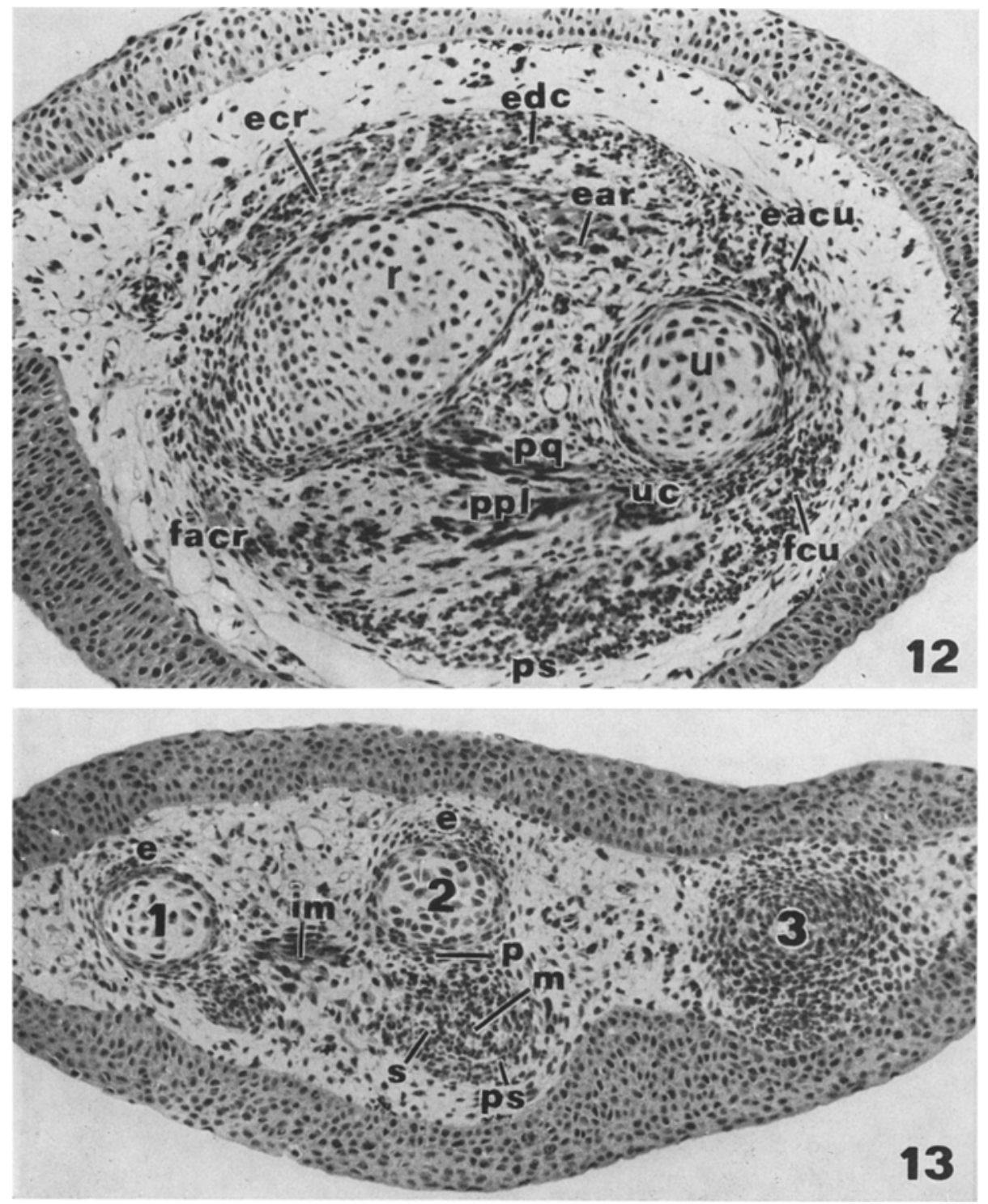

Fig. 12. Cross section through the middle part of the regenerating forelimb of an axolotl 32 days after amputation. Anlagen of all muscles of the zeugopodium have formed. Throughout the entire section significant numbers of connective tissue cells are present. $r$. primordium of the radius, $u$. primordium of the ulna, e.c.r. anlage of the $\mathrm{m}$. extensor antebrachii radialis, e.d.c. anlage of the $\mathrm{m}$. extensor digitorum communis, e.a.r. anlage of the $\mathrm{m}$. extensor carpi radialis, e.a.c.u. anlage of the $\mathrm{m}$. extensor antebrachii et carpi ulnaris, $p . q$. anlage of the $\mathrm{m}$. pronator quadratus, p.p.I anlage of the m. palmaris profundus $\mathrm{I}$, u.c. anlage of the $\mathrm{m}$. ulnocarpalis, f.a.c.r. anlage of the $m$. flexor antebrachii et carpi radialis, p.s. - anlage of the $m$. palmaris superficialis, f.c.u. anlage of the $\mathrm{m}$. flexor carpi ulnaris. $\mathbf{H} \& \mathbf{E} \times 80$

Fig. 13. Cross section through the autopodium of a regenerating limb of a 2 year old axolotl 29 days after amputation. At the level of the metacarpals $(1,2,3)$ the anlagen of the short muscles of the hand are already distinct. $i . m$. anlagen of the $\mathrm{mm}$. intermetacarpales, $e$. anlagen 
limb is completed, and the next month is devoted to further growth and maturation of these structures.

\section{Discussion and Conclusions}

The Embryonic Limb

The course of morphogenesis of muscle anlagen of the forearm and hand can be summarized as follows: The flexor and extensor blastemas begin to be formed in the zeugopodium at stage 40 , in the autopodium at stage 43 , in the rays of the first and second digits at stages 44-45 and in the third and fourth digits in 24-26 mm larvae.

Muscle anlagen form in the proximal part of the zeugopodium at stage 43 , in the distal part of the zeugopodium at stages $44-45$, in the carpal region of the autopodium at stage 46 and at the metacarpal level in $24 \mathrm{~mm}$ long larvae. Thus, both morphogenesis and cytodifferentiation of the muscle anlagen proceed along a prominent proximodistal gradient.

The anlagen of the flexor and extensor muscles, which begin from the humeral epicondyles, arise by the lengthwise splitting of the respective muscle blastemas. The deep layers of the flexor muscles form independently in the deep and loosely organized layer of the flexor blastema. In the autopodium the anlagen of the $\mathrm{m}$. abductor digiti $I$ and the short digital extensors appear in an independent deep blastemal layer. The short flexors of the digits are formed from a common blastema. The $\mathrm{mm}$. intermetacarpales are separated from their most deeply lying part, and simultaneously the entire blastema divides into three layers, which correspond to the three layers of the short flexors. In each layer the anlagen of the muscles for each individual digit presently form. Only later does each anlage separate into the definitive part of a muscle.

The morphogenesis and cytodifferentiation of muscle blastemas in both the zeugopodium and the autopodium progress along a distinct radioulnar gradient. The radially situated flexors and extensors become independent earlier, and their muscular elements are better differentiated than the ulnarly lying muscles at any given developmental stage. In the autopodium the succession of formation of muscle anlagen corresponds to the radioulnar sequence of differentiation of the digits.

Differentiation of the connective tissue components of muscles, as well as their tendons and aponeuroses, begins when the larvae are $27 \mathrm{~mm}$ long.

The radioulnar gradient and the progression of differentiation of the digits in an ulnar direction is a specific property of the Urodelean limb. It is one of the prominent differences between Urodeles on the one hand and the limbs of Anura and all amniotes on the other. In the latter the digits are laid down nearly simultaneously or in an ulnoradial direction (Holmgren, 1933, 1939, 1949). Holmgren's

of the short digital extensors, $p$. anlage of the $\mathrm{m}$. flexor digitorum brevis profundus - its area of insertion, $\mathrm{m}$. anlage of the $\mathrm{m}$. flexor digitorum brevis medius, $s$. anlage of the $\mathrm{m}$. flexor digitorum brevis superficialis together with the anlage of the tendon of the $\mathrm{m}$. palmaris superficialis (p.s.). The third metacarpal is shown at the level of the future carpometacarpal joint. Because it is relatively more distal, its muscle blastemas are less highly differentiated. The primordium of the fourth digit is not in this plane of section. $H \& \mathbb{E} \times 80$ 
comparative embryological observations on the development and construction of the skeleton in tetrapod limbs showed that from the standpoint of the skeleton the Urodelean limb differs from the limbs of Anura and the other amniotes. He considered that the Urodele has evolved a different and phylogenetically divergent type of limb.

In this investigation we have shown that this radioulnar gradient also holds true in the formation and differentiation of the muscle anlagen. Except for the radioulnar gradient, however, our observations have revealed no other differences between the genesis of muscular pattern in the Urodelean limb and that of the common tetrapod type.

From the sequence of development of digital anlagen in Anurans and amniotes one might expect a similar sequence of events in the development of muscle anlagen in the digits. In the stages of development before the formation of muscle anlagen in the chicken greater growth activity has been demonstrated in the ulnar region of the wing than in the radial region (Seichert, 1967). The mesodermal condensations in the autopodium of the limb in the mouse forms in an ulnoradial direction from the fifth to the first metacarpal (Milaire, 1965).

\section{A Comparison of Muscle Morphogenesis during Ontogenesis and Regeneration}

One of the most striking features of this investigation was the remarkable similarity in the morphological course of muscle development between embryonic and regenerating limbs. It has been repeatedly shown that the progress and manner of development of the muscle anlagen during ontogenesis is in accordance with the phylogenetic development of muscles. Recently, Sullivan (1962) demonstrated the similarity of the embryonic development of some groups of muscles in the chick wing with the development of limb muscles in other classes of vertebrates. During ontogeny in the human, anlagen of some muscles (m. sphincter colli, $\mathrm{mm}$. contrahentes) form and then later disappear (Cihák, 1957, 1967). The course of development of limb muscles is thus firmly fixed, and it is not surprising therefore that during regeneration the development of muscle anlagen pursues a sequence of changes in form very similar to that occurring during normal ontogenesis.

It is, of course, not possible to make any comparisons of preblastemic events in the formation of muscles in either system. The mesenchyme of the limb bud is composed of a mass of morphologically similar cells, and in the amphibian limb it is not known whether certain of these cells are already very early programmed to become myocytes or chondrocytes or whether their fate is determined primarily by their position in the limb bud. In the regenerating limb, the origin of the myogenic cells is not known, nor has the location of these cells been determined in the undifferentiated regeneration blastema. Particularly if muscle cells in the normally regenerating limb arise only from pre-existing muscle, there would be some obvious topographical differences in the early accumulative phases in muscle de velopment between the embryonic limb and the regenerate. Nevertheless, whatever differences that may be present appear to be resolved by the time the differentiative phase begins.

In regeneration, just as during ontogenetic development, blastemas of the flexor and extensor muscles characterize the first visible phase of muscle formation. In subsequent stages of development the anlagen of muscles are formed within 
these blastemas in a definite temporal sequence. The temporal succession in the formation of muscle anlagen during regeneration, as well as the positions of these anlagen, is identical to that which occurs in normal embryonic development. In the regenerating limb, anlagen representing the full number of missing muscles develop, and these muscles lie in correct anatomical relationships to the normal limb. During regeneration the muscle anlagen form in the same parts and layers of the muscle blastemas as in ontogenesis, and the sequence of the splitting of the blastemas is the same.

In the regenerating limb, as during ontogenesis, the process of muscle morphogenesis progresses along a proximodistal gradient. The more distally lying part of a given muscle anlage forms later than its proximal part. Muscle anlagen situated in the autopodium are formed later than those of the zeugopodium. This gradient is followed also by the developing cartilaginous primordia of the skeleton.

During both ontogenesis and regeneration radially situated structures form earlier than ulnary located structures. This gradient is particularly clear in the antopodium where in ontogenesis and regeneration the digits differentiate in radioulnar order. Likewise, the formation of muscle blastemas and anlagen follows a radioulnar gradient. In the zeugopodium this gradient is less prominent, but nonetheless distinct. The level of maturity and cytodifferentiation of the primordium of the radius in both regeneration and ontogenesis reflects a more rapid development than that of the ulna. The radial flexors and extensors become independent earlier than the muscle anlagen in the ulnar side of the forearm. Overall, nowever, the radioulnar gradient is less prominent than is the proximodistal gradient.

In view of this radioulnar gradient of maturity, it is interesting to note that in the development of multiple structures in a regenerating limb after the displacement of tissue components of the limb stump, late appearing supernumerary structures, particularly minor ones such as forked digits, usually appear on the ulnar side of the regenerate after the radial structures have become stabilized. (Carlson, unpublished).

Despite these distinct fundamental similarities, sections of the regenerating limb nevertheless differ from those of the embryonic limb to a sufficient extent that it is possible to distinguish at a glance the two types of limbs.

The embryonic limb contains only a very small amount of mesenchyme. Almost all of its cells are contained in the anlagen of the muscles and skeleton. Significantly more mesenchymal cells are added only during the very late stages of development. In the regenerating limb this is not the case. As early as the morphogenetic stage of the muscle anlagen, the regenerating limb contains a great number of mesenchymal cells that are not directly integrated into the early muscle and skeletal blastemas. These cells lie among the forming muscle anlagen and to an even greater extent between the muscle anlagen and the epidermis. In addition, the quantity of mesenchyme in regenerates of older animals is distinctly greater than in younger individuals. Muscle anlagen in embryos are relatively very compact. In contrast, in regeneration they are clearly fasiculated from the beginning.

At any given stage of muscle development, the connective tissues of the regenerating limb are more highly differentiated than those of the embryonic limb, particularly with respect to the presence of collagen fibers. During the stages of embryonic muscle development that were observed in this study, the connective 
tissue was very loosely organized and was primarily mesenchymal in its general appearance. In the regenerates, on the other hand, the connective tissues were arranged in more compact layers, and extracellular collagen was observed during and after the stages of the muscle anlagen. Definitive statements concerning the time of first appearance of collagen fibrils must await electron microscopic studies.

Regenerating and embryonic limbs differ in both their form and rate of development, as is evident from comparing Figs. 1-3 with Figs. 9-11. The distal portion of the embryonic limb is relatively broad whereas that of the regenerating limb tapers toward the apex. It is necessary to take into consideration, however, that the area of the amputation surface is significantly greater than that of the base of the embryonic limb.

Sections of regenerating limbs are two to three times greater in area than sections of embryonic limbs at a comparable stage of morphogenesis. This difference is due not only to the thicker epidermis and the significantly greater amount of mesenchyme in the regenerating limb but also to a greater cross sectional area of the muscle anlagen themselves. Some preliminary counts have shown that the number of cells in a section of a given muscle anlage of a regenerating limb is about twice that of the same anlage in an embryonic limb at a comparable stage of differentiation. This difference in the sizes of muscle anlagen does not, however, allow an earlier separation of the anlagen from one another in the regenerating limb. It is possible that the organ anlage requires a certain critical mass or number of cells before it can begin to differentiate and that the critical number in the embryonic limb is substantially less than it is in the regenerating limb.

At this time it cannot be determined whether the larger number of cells in the muscle anlagen of the regenerating limb is due to a more intensive early period of cellular proliferation or whether it is a reflection of an initially larger source of myogenic cells resulting from the dedifferentiative process.

The finding of such a close morphological similarity in muscle formation between embryonic and regenerating limbs lends indirect support to the viewpoint that the regeneration blastema functions more like an embryonic limb bud than has sometimes been believed. In contrast to the idea (Holtzer, 1970, p. 85) that the regeneration blastema is involved only in the formation of the skeleton and connective tissues and that the muscles in the regenerate grow out from the muscles of the limb stump, these observations suggest that the regeneration blastema is an integrated morphogenetic unit in which both skeletal and muscular elements form by following a morphogenetic blueprint similar to that which controls the differentiation of the embryonic limb.

Acknowledgement. The authors gratefully acknowledge the technical assistance of Mrs. Sherry Rogers and Miss H. Tomášková.

\section{References}

Carlson, B. M.: Relationship between the tissue and epimorphic regeneration of muscle. Amer. Zoologist, 10, 175-186 (1970)

Carlson, B. M.; Organizational aspects of muscle regeneration. In: Research in muscle development and the muscle spindle. Eds.: Banker, B. G., Przybylski, R. J., van der Meulen, J. P. and Victor, M. pp. 3-17 Amsterdam: Excerpta Medica 1971

Carlson, B. M.: Muscle morphogenesis in axolotl limb regenerates after removal of stump musculature. Develop. Biol. 28, 487-497 (1972a) 
Carlson, B. M.: The regeneration of minced muscles. Monographs in Developmental Biology. Vol. 4. Basel: S. Karger AG 1972 b

Carlson, B. M.: Factors controlling the initiation and cessation of early events in the regenerative process. In: Neoplasia and cell differentiation. Ed.: Sherbet, G. V. pp. 60-105 Basel: S. Karger AG 1974.

Chen, H. K.: Development of the pectoral limb of Necturus maculosus. Illinois Biol. Monogr. 14, 1-77 (1935)

Čhák, R.: M. sphincter colli in der Ontogenese des Menschen. Cs. Morfol. ã, 3-15 (1957)

Čihák, R.: Development of the m. latissimus dorsi in human ontogenesis. Sborn. lék. 65, 21-26 (1963)

Čihák, Pr.: The occurrence of $\mathrm{mm}$. contrahentes and their changes during the development of the human hand. Folia morph. (Praha) 15, 197-205 (1967)

Činák, R.: Ontogenesis of the skeleton and intrinsic muscles of the human hand and foot. Ergebn. Anat. Entwickl.-Gesch. 46, 1-194 (1972)

Dylevský, I.: Contribution to the ontogenesis of the flexor digitorum superficialis and the flexor digitorum profundus in man. Folia morph. (Praha) 15, 330-335 (1967)

Dylevský, I: Muscles of the intermetacarpaI spatium in the bird wing. Development and homology. Folia morph. (Praha) 16, 277-285 (1968)

Goss, R. J.: Regeneration of vertebrate appendages. Advanc. Morphogenesis 1, 103-152 (1961)

Grim, M.: Development of the primordia of the latissimus dorsi muscle of the chicken. Folia morph. (Praha) 19, 252-258 (1971)

Grim, M., Carlson, B. M.: A comparison of morphogenesis of muscles of the forearm and hand during ontogenesis and regeneration in the axolotl (Ambystoma mexicanum). I. Anatomical description of muscles of the forearm and hand. Z. Anatomie 145, 137-148 (1974)

Harrison, R. G.: Organization and development of the embryo. Ed.: Wilens, S. New Haven and London: Yale Univ. Press 1969

Holmgren, N.: On the origin of the tetrapod limb. Acta zool. (Stockh.) 14, 185-295 (1933)

Holmgren, N.: Contribution to the question of the origin of the tetrapod limb. Acta zool. (Stockh.) 20, 89-124 (1939)

Holmgren, N.: On the tetrapod limb problem - again. Acta zool. (Stockh.) 30, 485-508 (1949)

Holtzer, H.: In discussion of Steen, T. P.: Cell differentiation during salamander limb regeneration. In: Regeneration of striated muscle and myogenesis, p. 85. Eds.: Mauro, A., Shafiq, S. A. and Milhorat, A. T., Amsterdam: Excerpta Medica 1970

Milaire, J.: Aspects of limb morphogenesis in mammals. In: Organogenesis. Eds.: De Haan, R., Ursprung, H., p. 283-300. New York: Holt, Rinehart and Winston 1965

Rose, S. M.: Regeneration. In: Physiology of amphibia. Ed.: Moore, J. A., pp. 153-176. New York: Acad. Press 1964

Rylkoff, H.: Die Entwicklung der Schultermuskeln bei urodelen Amphibien. Z. wiss. Zool. 122, 116-171 (1924)

Saunders, J. W., Jr.: The proximo-distal sequence of origin of the parts of the chick wing and the role of the ectoderm. J. exp. Zool. 108, 363-403 (1948)

Seichert, V.: Differential growth pattern in the chick embryo wing-bud between the 3,5 th and 7 th day of incubation. Folia morph. (Praha) 14, 325-333 (1966)

Sullivan, G.E.: Anatomy and embryology of the wing musculature of the domestic fowl (Gallus). Austr. J. Zool. 10, 458-522 (1962)

Thornton, C. S.: Amphibian limb regeneration. Advanc. Morphogenes. 7, 205-249 (1968)

Trnková, E., Dylevský, I.: Musculi contrahentes in the ontogenesis of the rat limb. Folia morph. (Praha) 17, 213-218 (1969)

Zwilling, E.: Limb morphogenesis. Advanc Morphogenes. 1, 301-330 (1961)

\author{
Dr. Bruce M. Carlson \\ Department of Anatomy \\ 4622 Medical Sciences II \\ University of Michigan \\ Ann Arbor, Michigan 48104 \\ USA
}

